\title{
MEDIA CONSUMPTION HABITS OF YOUNG WOMEN IN KASHMIR: A CASE STUDY OF WOMEN'S COLLEGE, SRINAGAR
}

\author{
Muntaha Mehraj Hafiz* \\ Central University of Kashmir, India
}

\begin{abstract}
Youth in India-administered Kashmir have many choices when it comes to different media products. With regard to this fact, information about media choices of youth especially women group is very difficult to gauge due to multiple reasons such as distributed exposure to a variety of media, dissimilar norms and beliefs, wide interests, and conflict. Thus this study attempts to find what young women in Kashmir like \& prefer when it comes to different platforms of media i.e. Print, Broadcast and, Online. The survey method was employed to conduct the study and questionnaire was used as a data collection tool. Usage patterns were further classified among rural and urban areas. The study found that newspapers are the first preference of women when it comes to receiving information about news and current affairs, internet trends to be a popular medium for education, and TV wins over all other options for entertainment. A critical path analysis further reveals how students who are excellent in studies tend to be more open to media as compared to their average counterparts and how internet led to addiction and media -dependency among women in Kashmir elevating internet usage amongst them. Through these findings, the researcher anticipates assisting media marketers to develop an effective media strategy to reach their target audience advantageously with an ease to not only understand but also interpret the choices of young women in Kashmir.
\end{abstract}

Keywords: Kashmir, media-preferences, women, print, broadcast, online media

\section{Introduction}

Today's generation is enthralled with media, be it radio, newspaper, TV or internet. All sorts of information are available to them in diverse ways through multiple platforms. One thing is certain - all these outlets have been successful in playing an essential role in the lives of people, the reason why they still exist. However, with the advancement in technology, the media consumption patterns have changed. It now needs to keep on par with the choices, attitudes and feasible availability of consumers.

Over the past few decades, the media industry has undergone revolutionary changes. It started from newspapers (1605) and then as the technology improved radio (1920) came into existence followed by the era where TV and internet ruled the market. During World War 1 radio played a vital role in disseminating information, but it was television that brought up the concept of mass communication. The power of reaching a large audience in a quick and economical manner proved TV to be a successful model of communication. Later with the advent of satellite channels watching TV became one of the most popular phenomena among all especially youth segment. As the time moved on there was seen a progress in media penetration among people. Growing literacy rate and advancement in technology contributed to an expanding consumer base of various forms of media (print, broadcast and online). People started having media understanding as the time moved on.

Among all the drastic changes in the media industry, one of the biggest and influential changes was the arrival of the internet. The Internet supposedly not only invaded our lives but also managed to capture our attention for a longer period. Youth has been found to spend their time chatting, shopping, gaming and surfing the internet for many other purposes (Pahwa, 2006). Considering the popularity of the internet, media companies are now paving their way towards new media so as to understand and target their specific group of interest directly 
especially the new generation which embraces this new media quickly (Bruner 1997). This new generation is also termed as the Net generation which not only is tech savvy but also considers themselves to be more expert than their past generation (living stone, bobber, 2003).

The audience has become hyperactive and uses social media at an astonishing rate where they not only share their ideas and opinions but also discuss them. Various research studies show that students use social media on a daily basis and are the keen users of new media. The introduction of blogs has become yet another successful step towards clutching the attention of media audience with all the options available to share their opinions. The internet is not only now accessed but also progressively gaining acceptance amongst the general population with more people going online every day. (Kargaonkar and Wolin, 1999).

\section{Media in Kashmir}

In a diverse country like India with a population of about 1.32 billion, marketers often spend a lot of time in devising strategies so as to beat the ongoing competition in media markets, and also communicate with their target audience efficiently. According to the infographics about 40 million Indian consumers get online every day with teens spending an average of 9 hrs a day with media.

However, when it comes to the state of Kashmir, marketers find it complicated to know their consumer mindsets due to its unsettled relations with India and other factors such as literacy, hectic environment, mountainous terrain, less connected areas, changing mind-set, and diverse choice of media that makes it even difficult for mushrooming marketers to connect to them and to understand what they watch, listen and read.

Looking through the prism of history, Media in Kashmir has played a limited yet very important role. Being a state of turmoil since 1947, it has witnessed a turbulent period through insurgency, infiltration from other countries and unpredictable war incidents. All these causes have been responsible for limiting the growth of the state and the media as well, and thus the progress of media in Kashmir has been too little and too constrained. Also, Kashmir is identified as a region with intense and difficult physical terrain, where the media outreach is not uniformly distributed to all. There are some rural and remote segments which do not have an adequate access to one or many forms of media. In case of traditional media, these far flung segments usually prefer radio or TV over print medium (newspapers) while new media may have the reach but the scope of access is too little in such areas.

Starting from the period of 1990's, the media usage patterns in Kashmir were news-centric and the people mainly used media to stay aware of circling political agendas and political activities in Kashmir. Use of traditional media was popular, especially radio which was known to be the only medium that was used on a regular basis. At that time Kashmir owned a single electronic outlet that was Doordarshan. It was after the gulf war that cable channels were introduced in the state. This introduction of cable channels further paved way for many amateur news and entertainment channels in Kashmir valley. And as the time moved on, the choices and preferences of people also started to change. Consecutively many private radio channels also emerged in the state. It was after the emergence of Big 92.7 FM that radio became popular amongst youth in Kashmir. Radio that was once considered to be orthodox turned to a spicy medium of communication.

New media in Kashmir has been a centre of attention, and has played a vital role in disseminating information during the times of crisis and turbulence in the valley. During 2008- 2010 uprising when a blanket ban was put on certain media services in Kashmir such as SMS (short messaging service), people turned to social networking sites and other phone applications to stay in touch with their near and dear ones and also to stay updated on political affairs in Kashmir. Currently, any unstable condition in the valley leads to barring of media channels. Social networking sites such as Instagram, Facebook, YouTube are also banned and the phone services are put down, newspapers are seized thus limiting the role of media in Indian-administered-Kashmir. 


\section{Women in Kashmir}

Since 1947, Kashmir has been trapped in an awful manifestation of turmoil and women amidst the mayhem have been playing an active role in the development of the society. Being at the forefront of conflict, women in Kashmir do not have the luxury of being mothers, wives, and daughters living somewhere in the free parts of the world. Their scale of responsibilities has stretched from nurturing the families to become shields for their men to shoulder sudden responsibilities when their male member is killed, imprisoned or disappeared. Thus the choices of women in Kashmir need to be gauged, understood and viewed as a reflection of the society at large. Being a sturdy component of the society women in Kashmir have not only excelled in the field of arts and literature, but have also shown a knack towards law, police, and administration, and besides handling issues of life and death, they have also been skilful at doing mundane things such as tending farms, cultivating rice, raising cattle, weaving carpets, and vending vegetables.

Thus, in the above context, this research tries to explore the media consumption habits of young women (rural and urban) in Kashmir further to identify their purpose, choices, and preferences across different platforms of media.

\section{Literature Review}

Different researchers and scholars have attempted to explain the different media consumption habits of different people across different countries and different age groups. They have tried to gauge the causes and consequences of media on consumers in their own terms however with the change of habits and with the advent of new technologies, the consumption pattern has also shifted making this concept of 'media consumption' even complex.

The term media consumption refers to the sum of information and entertainment media, taken in by an individual or group which includes activities such as interacting with new media, reading books and magazines, watching TV and listening to the radio. In the context of this definition, there have been different works of literature proposed to understand how and why media plays an important role in the lives of people.

Each media platform functions to deliver something to the audience but nowadays it is the youth which is becoming the 'bulk audience' to receive information across different forms of media. The internet has been found to play a prominent role among the young college going students. The survey done to study this concept shows that college students (18-24 years old) spend more time on the internet than any other media (Burst media, online study, July 2007) and the main reasons for such huge internet usage were 'to keep in touch with friends and stay entertained'. Moreover, the instant messaging was found to be the most popular activity among both males as well as females.

In terms of radio and television $16 \%$ youth spent around ten hours per week on television and only $5.5 \%$ listened to radio for ten hours per week. The other findings from the burst study of college students were that brand selection among students is driven by cost consciousness, it is the most important factor regarding when it comes to the selection of a particular brand.

Further, the internet has become one of the easiest and cheapest means available to chat, play games, watch online videos, online shopping etc. In this context, there are some experts who believe that these activities have led to the unregulated use of the internet, thus to addiction and deficient self-regulation. There have been many reports published on problematic forms of internet usage and have been the subject of both popular and scholarly writings. Rober Larose, Carolyn A lin and Mathews.Eastin (2009) found that unregulated media behaviours are the product of deficient self-regulatory processes through which media consumers try to judge and adjust their own behaviour. A path analysis demonstrated that certain media habits formed to alleviate depressed moods, undermine self-regulation and led to increased internet usage. As per the study proposed by Arvind Didi and Robert Larose (2010) where they studied media consumption patterns among college students 
found that maximum news sources were used for current events knowledge in which habit strength was the most powerful predictor of news consumption overall.

Where some experts argue that internet usage is on the rise, there is a segment of experts who believe Television still rules the market and is the most popular mass media among the youth. Growth of internet and mobile phones has not led to the reduction in television viewing, but instead with the dramatic explosion in satellite and cable TV, youth interacts with the different forms of media in different ways, each of them adding to their entertainment requirement with the possibility of communicating outside their traditional peer networks (Cooke, 2002). Many experts also believe that soap opera viewing contributes to the cultivation of tastes in the audience. (Buerket- Rothfuss and Mayes, 1981) found that the more one is exposed to soap operas the more likely audience is going to accept it as real.

There are also some studies which are focussed on media usage and its effect on the academic lives of college youth. As per Kaiser family foundation study- as new technologies become available there is more possibility of distraction from studies. There are three main ways in which instant messaging might interfere with academic reading. a) displacement of time available for study b) direct interference while studying c) development of a cognitive style of short and shifting attention, impatience ( Lavin e Levine, Bradley m Waite and Laurel 1.Browman.2007). Apart from studies which show the academic distractibility among college youth, there are also some studies which show that students improve in curriculum studies with the use of the internet. In a study by Halligram (2005) - 79\% indicated that internet has a positive impact on their college career.

Further various surveys have also been conducted to find the depth of newspaper readership and radio listenership among the audience. As per audience measurement survey (2011), it is access, literacy and, the cost that affects population's newspaper readership where Newspaper readership is mainly dependent on a copy from the household member or from office and rarely buy their own copy. In countries like Kenya radio listenership generated the highest engagement levels where an average weekly radio listener listens to radio for approximately 37 hours. Moreover increase in mobile telephony service providers, availability of cheaper handsets and value-added services have facilitated and improved mobile penetration rate. That is $67.2 \%$ per 100 inhabitants.

The age has also been used as the factor in the study of media consumption patterns. It has been found that youth is seen to be less active in consuming news while older audience seeks out news more actively (Pew Research Centre for people and press, 2008).

\section{Method}

\section{Participants and Procedures}

The study analyses data obtained from a limited sample of 60 respondents in the age group of 18 - 22 from women's college in the state. A convenience sample of undergraduate students from two different regions (rural $\&$ urban) and two different courses (Arts \& science) was carried out.

The study was conducted using a survey method which included both quantitative and qualitative analysis. Though the survey demanded a questionnaire or a direct observation process the researcher found it easy to develop a questionnaire rather than to conduct interviews. The researcher administered the questionnaire personally to ensure the excellent response rate as well as to avoid any misunderstanding while providing responses. The Questionnaires were distributed among 60 respondents, studying in 1 st, 2nd, and $3^{\text {rd }}$-year degree courses among which 30 belonged to the urban background while the rest belonged to the rural areas. This helped the researcher to study the place discrepancies when it comes to media consumption pattern of different media. The main target of the research was college going women youth \& the college chosen for the study was The Women's College, Srinagar. 


\section{Findings of the study}

\section{Women who read newspapers with different regularity}

Figure 1(below), shows that amongst the maximum number (65\%) of students read newspapers on daily basis among which maximum are from the urban background and are excellent in studies. While those coming from rural areas don't show much interest in reading newspapers on a daily basis but prefer to read them few times a week or even a month. As per the academic performance, students who are average in studies don't show any significant relation with reading newspapers.

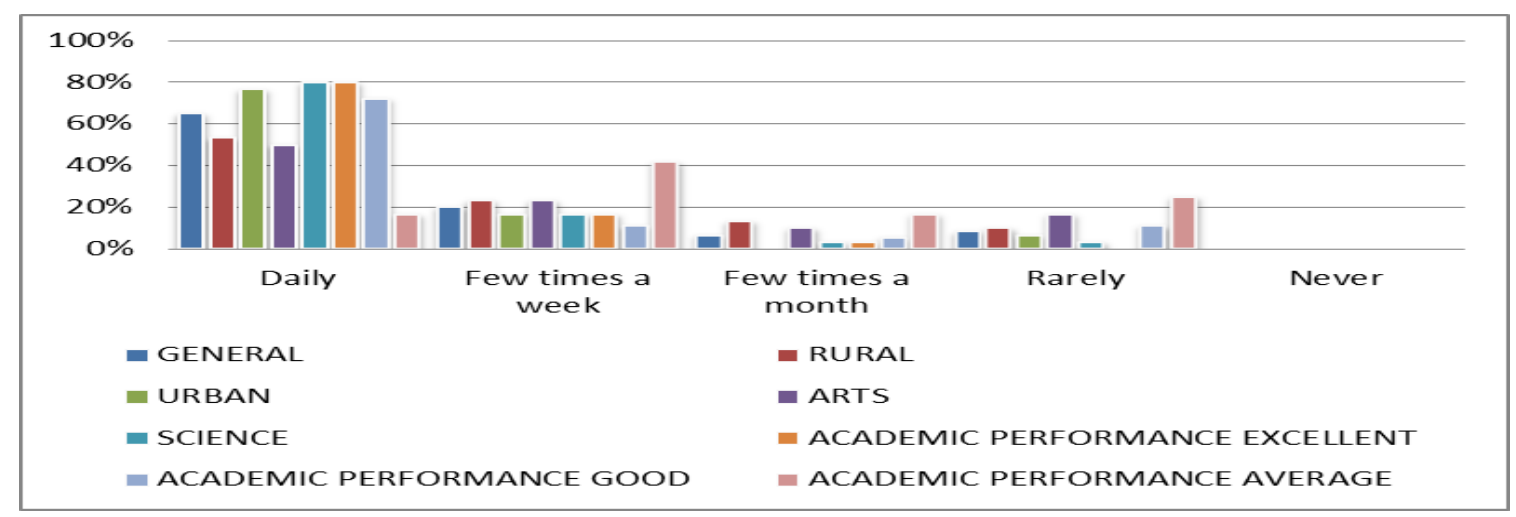

Figure 1 Data of Media consumption habits of college going women youth

\section{Percentage of students reading different sections in a newspaper}

Figure 2 (below), shows that Headlines $(68.3 \%)$ is the most read sections amongst the various other sections in a newspaper. Followed by advertisements (30\%), front page news (30\%), Notifications (13\%) and all others. Among (13.3\%) who read International news, the majority of these respondents belong to rural sections, are excellent in studies. Front page news, political news, and advertisements are equally read by both rural \& urban sections. Also, that none of the respondents are interested in editorials and business news.

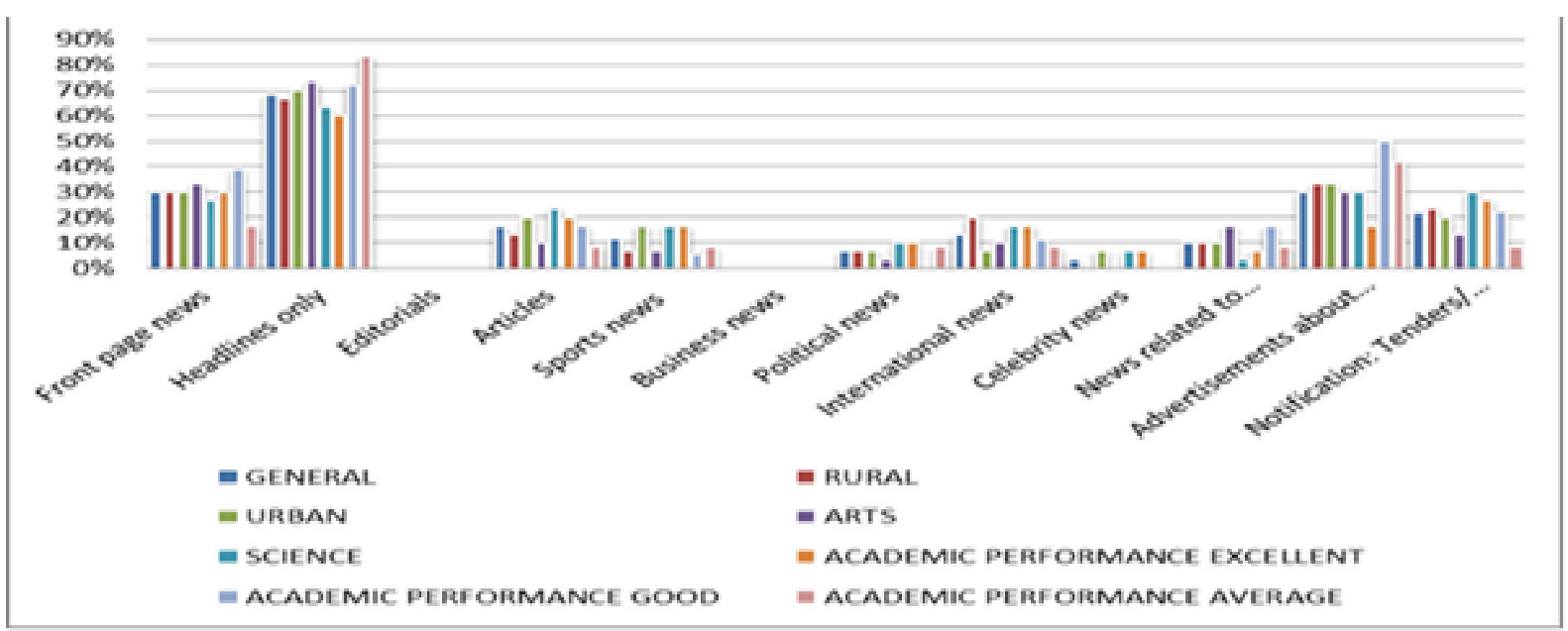

Figure 2 Data of Media consumption habits of college going women youth

\section{Percentage of students who spend different amounts of time on watching TV daily}

Figure 3(below), shows that Out of total time spent on watching T.V, majority of viewers (53.3\%) spent 1-2 hrs on watching TV maximum of which are excellent in studies with science as their faculty, followed by (20 percent) who spent 2-4 hrs Hrs ,(18.3 percent) who watched TV more than $4 \mathrm{hrs}$ and then (8.3 percent) who 
didn't watch TV at all. It is apparent that students consumed more media and could influence their views/perceptions in an easy way.

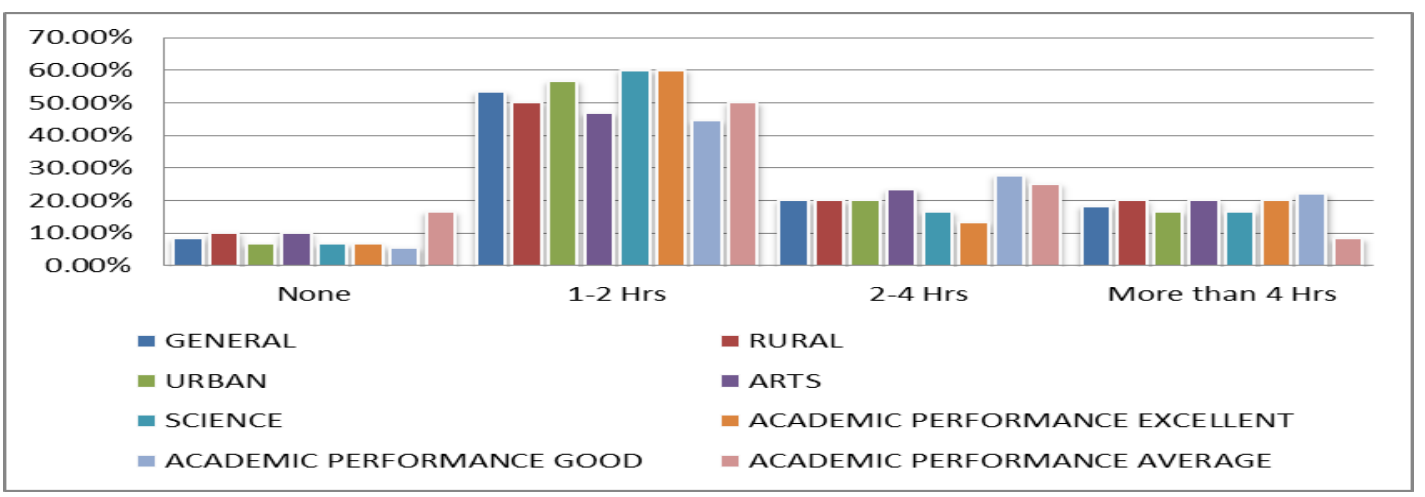

Figure 3 Data of Media consumption habits of college going women youth

\section{Percentage of students who watch different types of Programmes on TV}

Figure 4(below), shows that the Reality shows are the first preference of the majority of students (58.3\%) watched more by those who belong to urban areas(83.3\%), are from art faculty, are excellent in studies. Followed by $(33.3 \%)$ who watch films and are average in studies. However, News is more consumed by those who come from the rural background, belong to science faculty, and are excellent in studies. Students have shown less concern towards categories like health, sports, soap operas, History, Travel \& lifestyle, cookery shows, Educational, nature, social message etc. However, categories such as Business, Agriculture, Horror, Film/celebrity news are not watched at all. It is also clear that TV is more used for entertainment purposes.

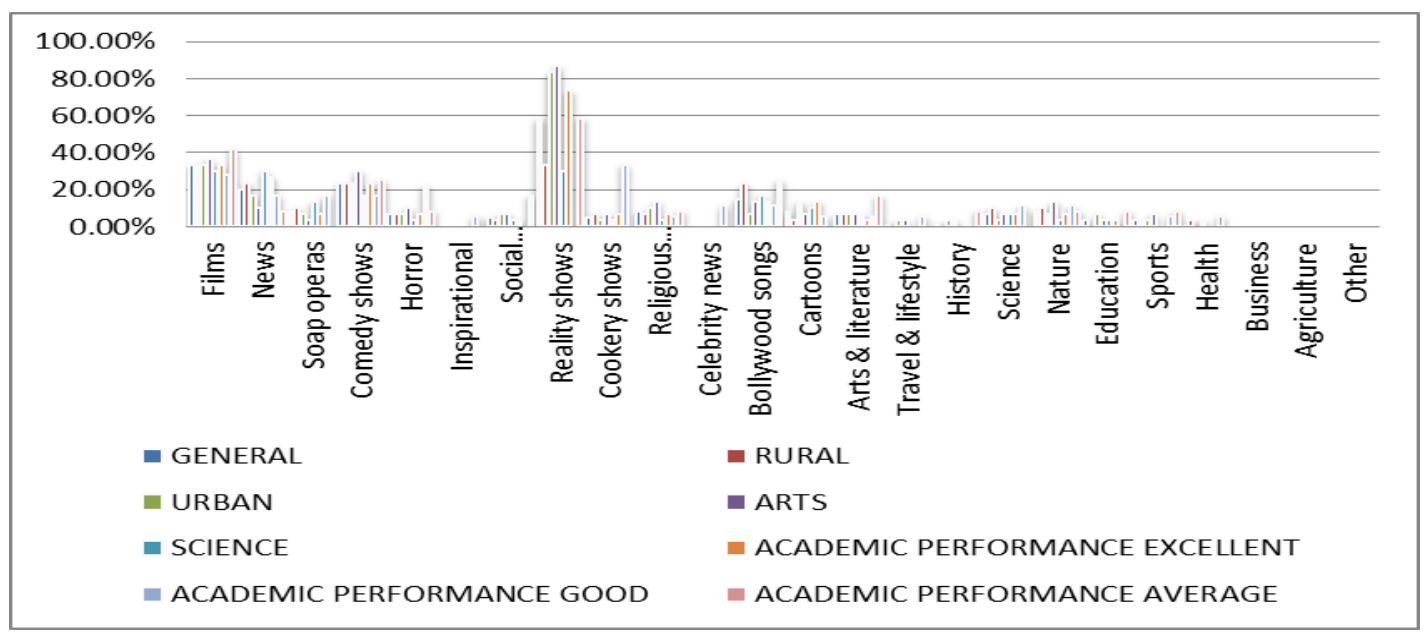

Figure 4 Data of Media consumption habits of college going women youth

\section{Percentage of students who spend different amount of time listening to radio daily}

Figure 5 (below), shows that out of the total sample of 60 , the majority(70\%) listened to the radio for 1-2 hrs, maximum of which come from urban areas and belong to science faculty, while $(10 \%)$ listened to the radio for 2-4 hrs and $(6.6 \%)$ for more than 4 hours. However $13.3 \%$ of the total respondents do not listen to the radio at all. It is apparent that radio listener ship was more prominent in rural areas as compared to their urban counterparts. 


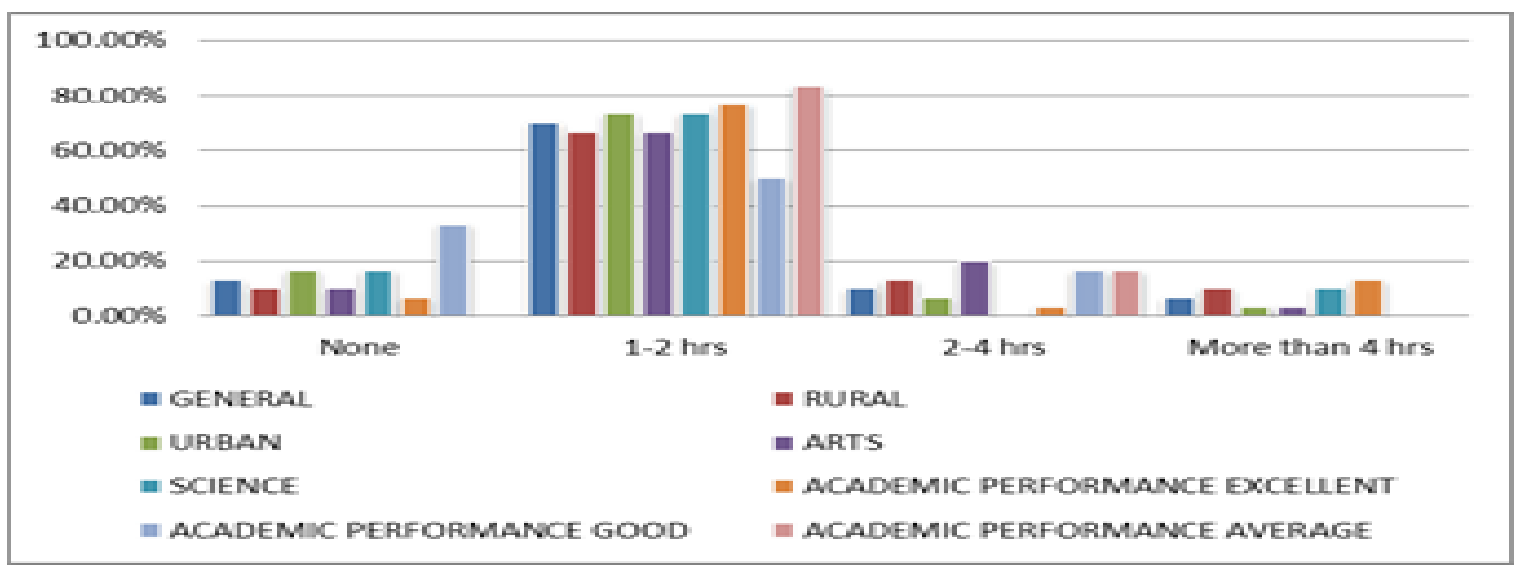

Figure 5 Data of Media consumption habits of college going women youth

\section{Percentage of students which listen to different types of programmes on radio}

Figure 6(below), shows that the majority of the respondents $(55 \%)$ tuned in to radio for music (entertainment purpose), maximum of which come from urban areas, belong to arts faculty, have studied in government schools and are average in studies. Followed by $(16.6 \%)$ who tune in to radio for news and views, belonging to rural areas and faculty of arts. Another (16.6\%) listen to religious programmes on radio. Categories like dramas, education, Health, features, Call In programmes are given less concern while categories like sports \& business are not listened at all.

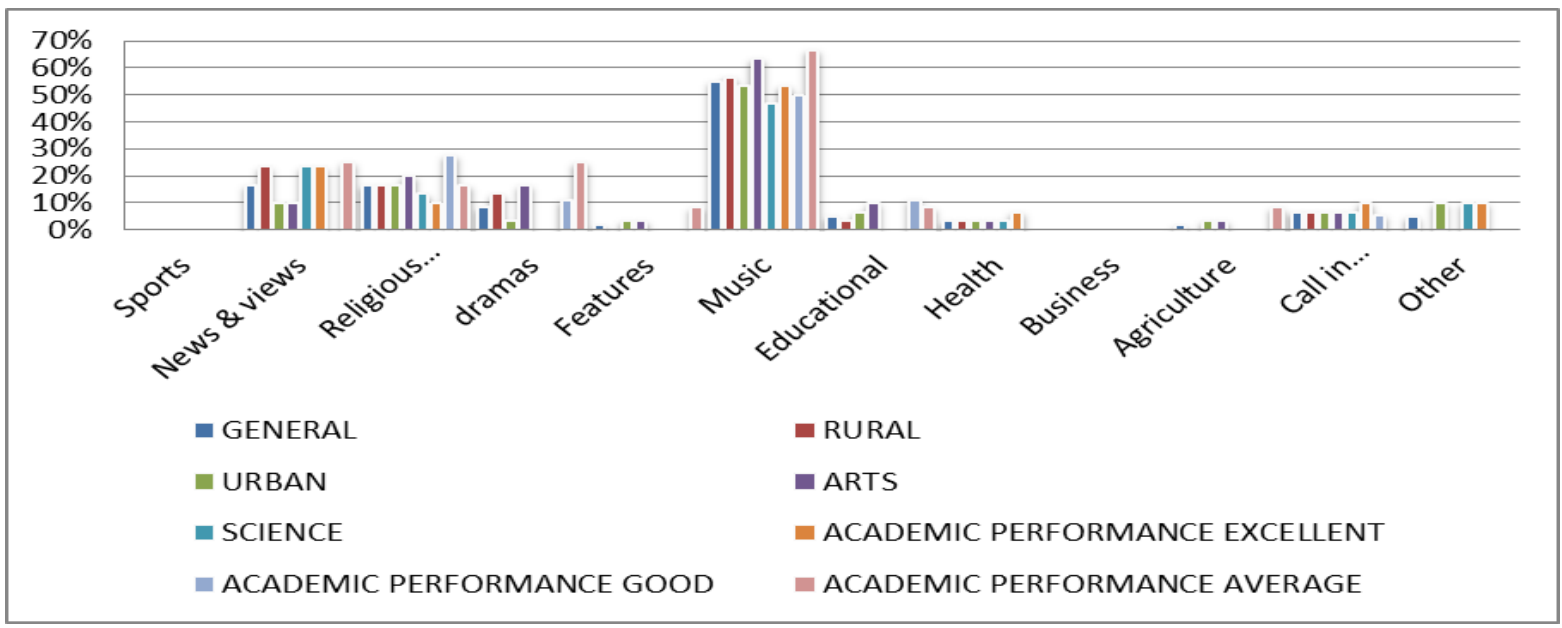

Figure 6 Data of Media consumption habits of college going women youth

\section{Percentage of students accessing internet at different places}

Figure 7 (below), suggests that out of the total sample of 60, majority (81.6\%) access internet at home via their personal connection, these students are excellent in studies, followed by $(6.6 \%)$ who use the internet at college, $(3.3 \%)$ at Internet cafes and then $(1.6 \%)$ at Community Internet centres. None of the respondents from urban areas access internet at community internet centres \& Internet cafes, while it's those students who come from rural areas and belong to science faculty who access internet from these places. Those who go to internet cafe are excellent in studies while those going to community internet centres are average in studies. 


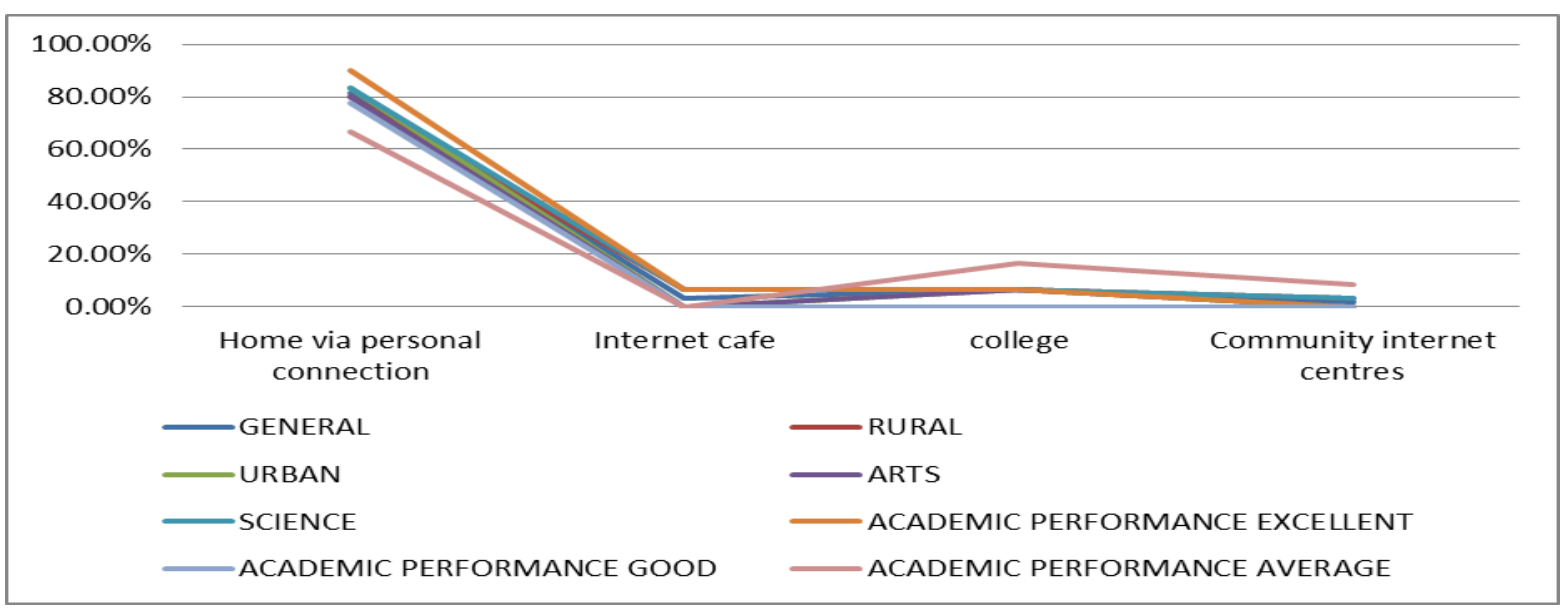

Figure 7 Data of Media consumption habits of college going women youth

\section{Percentage of students who use internet for various purposes}

Figure 8 (below), shows that that majority of respondents $(70 \%)$ use internet for educational purposes. These respondents are from urban areas, and are excellent in studies, followed by (41.6\%) who use internet for social networking, (18.3\%) who use internet for entertainment purposes, followed by $(10 \%)$ who use internet for playing games, then $(8.3 \%)$ who prefer to use internet for online shopping \& news and $(3.3 \%)$ who use internet for sending/receiving emails. Maximum of the respondents who are excellent in studies prefer to use internet for email, education, news, online shopping, sending/receiving emails while those who are average in studies use internet for playing games \& surfing social networking sites. None of the respondents is a blogger.

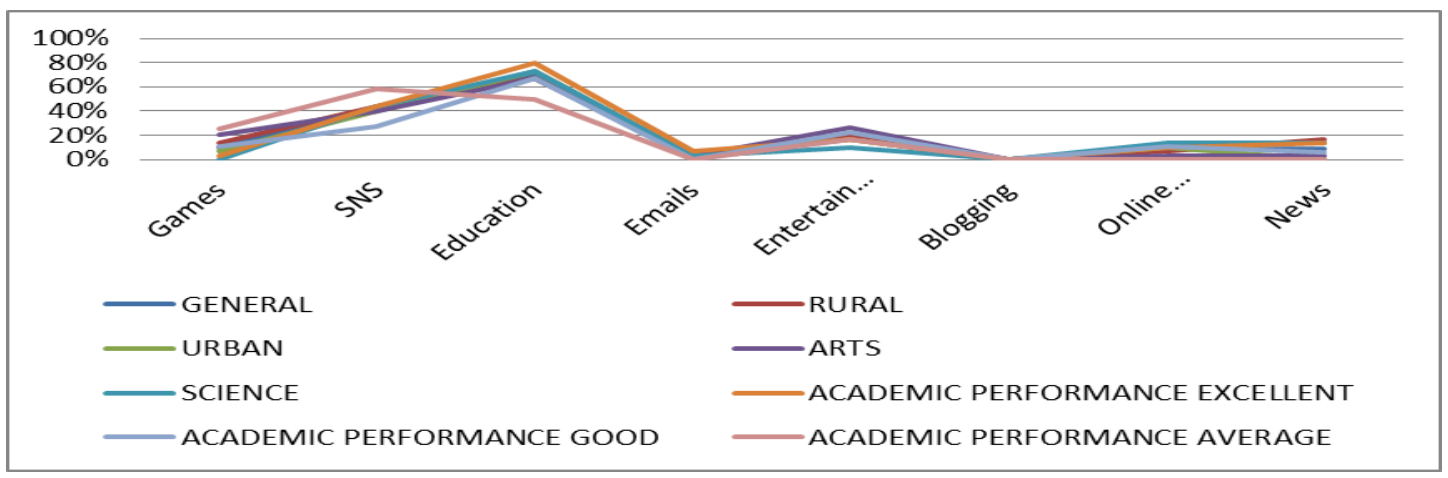

Figure 8 Data of Media consumption habits of college going women youth

\section{Sites generally accessed by students on internet}

Figure 9(below), suggests that majority $(61.6 \%)$ of the total sample prefer Face book over other sites. Maximum of these respondents are average in studies (75\%), and belong to arts faculty (63.3\%). Only (6.6\%) of the total respondents access Skype, maximum of which come from rural areas(10\%), belong to science background( $10 \%) \&$ are excellent in studies( $10 \%)$. Followed by (1.6\%) who use Twitter and some other sites. While $(31 \%)$ of respondents do not use any of the above- mentioned sites. 


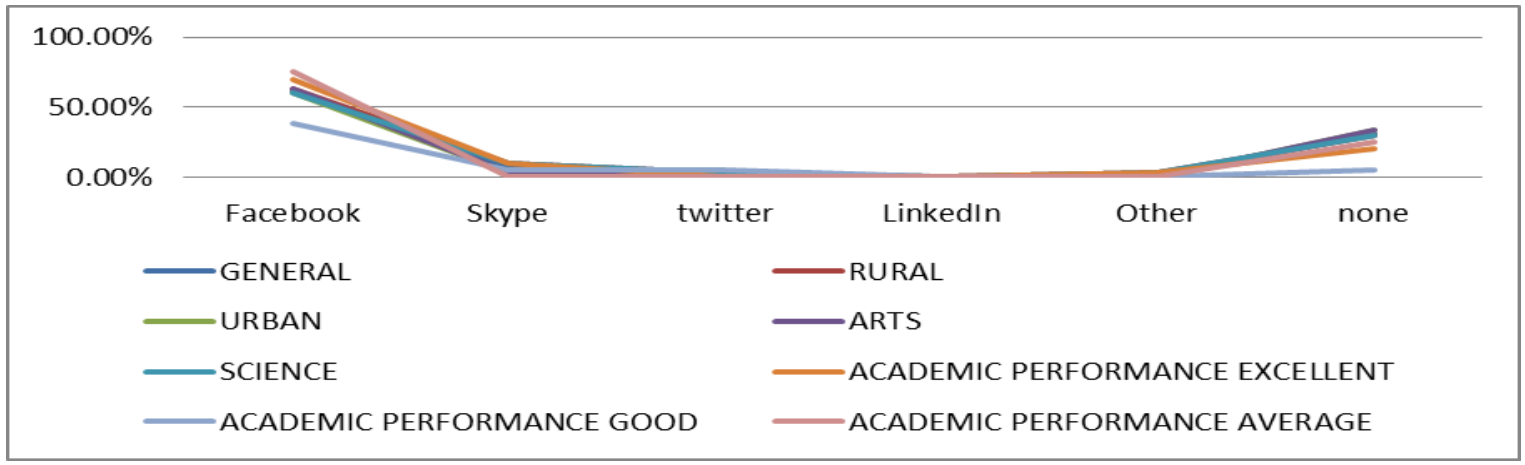

Figure 9 Data of Media consumption habits of college going women youth

\section{Percentage of students showing the effects/correlation of using internet on their academic lives}

Figure 10(below), suggests that majority $(46.6 \%)$ of the total respondents found the internet to aware them of current affairs. Maximum of these respondents come from urban areas, and are excellent in studies. Followed by $(31.6 \%)$ who believe the use of internet has helped them to improve in their academic studies. While (15\%) believe that use of the internet is responsible for the deterioration in studies and (11.6\%) believe the Internet has no effect on student's academic life.

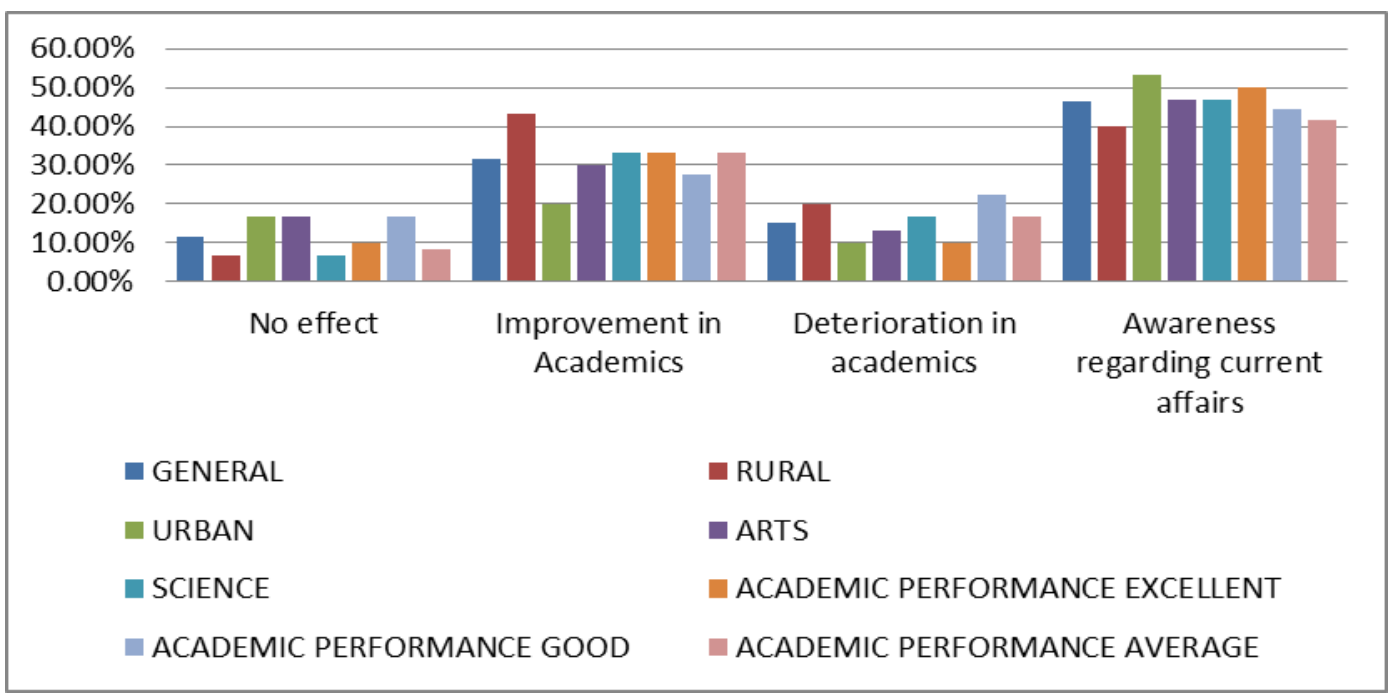

Figure 10 Data of Media consumption habits of college going women youth

\section{Percentage of students showing effects of using internet on their personal lives}

Figure 11(below), suggests that majority (51.6\%) of the total respondents take the Internet as addiction. Maximum of these respondents are excellent in studies $(63.3 \%)$. Followed by $(36.6 \%)$ who believe the Internet has been a medium of relaxation in their lives. (3.3\%) believe internet leads to Insomnia (restlessness) \& (3.3\%) believe internet causes depression. However, $(10 \%)$ of the total respondents believe that Internet has no effect on their lives. 


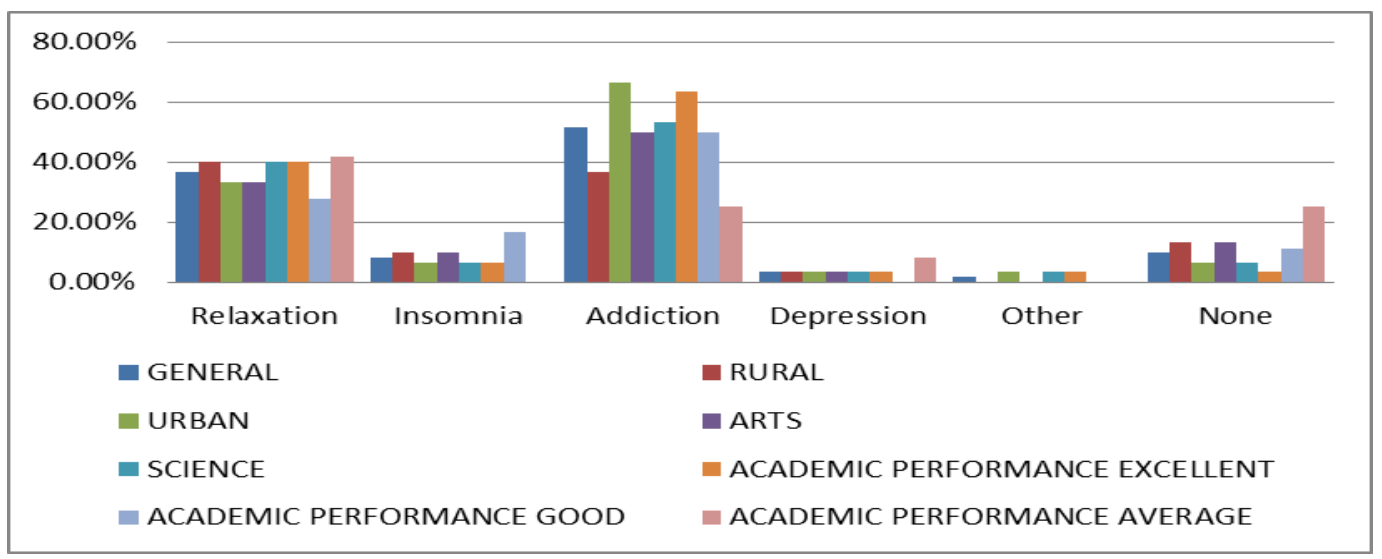

Figure 11 Data of Media consumption habits of college going women youth

\section{Effect of Internet on social lives of students}

Figure 12(below), suggests that majority (41.6\%) of the total respondents believe that Internet is the medium which connects them to their old/distant friends while (35\%) believe internet is responsible for both detachment as well as connection with family \& friends, followed by (41.6\%) who believe Internet to be the medium which connects them with their old/ far friends. $(10 \%)$ of the total respondents believe that Internet detaches one from friends \& family. While (13.3\%) believe there is no effect of the internet on their social lives.

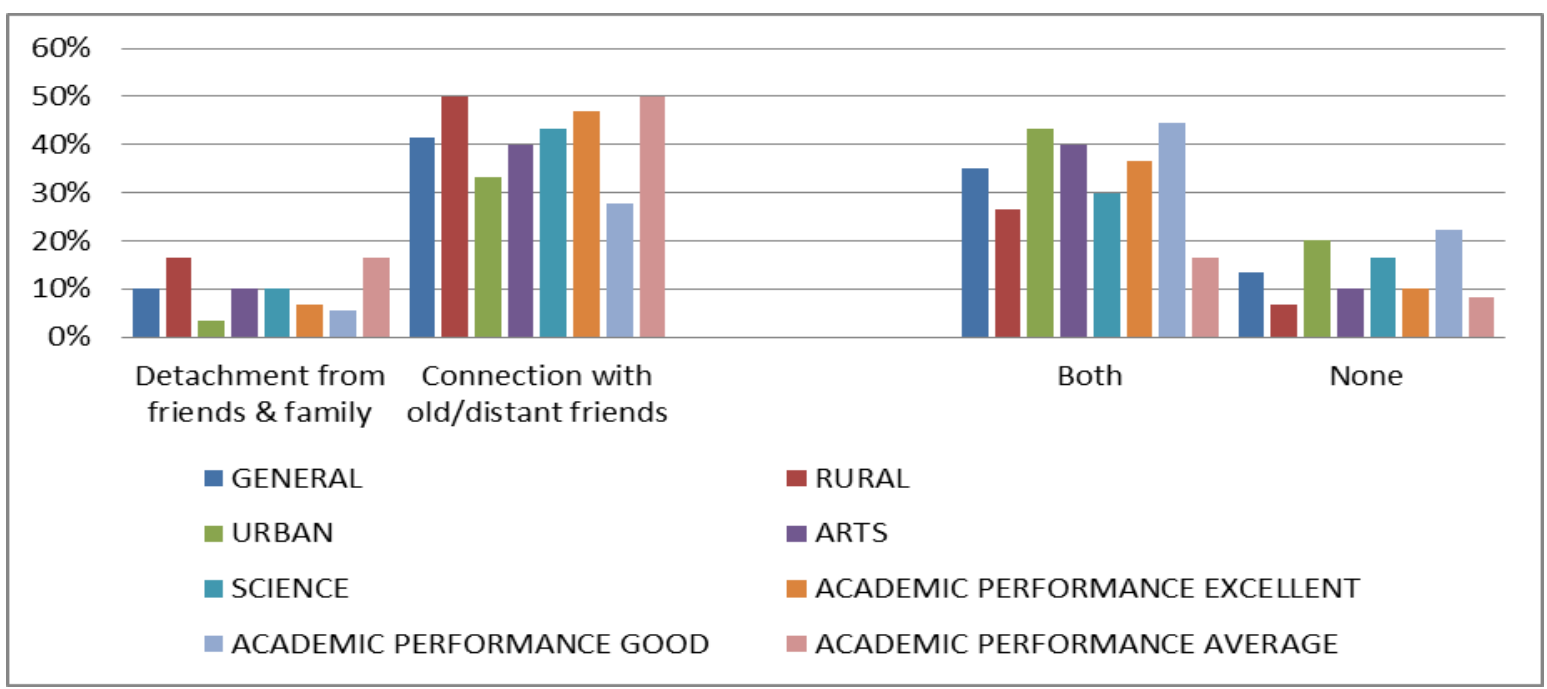

Figure 12 Data of Media consumption habits of college going women youth

\section{Percentage of students who believe media have an effect on their opinions.}

Figure 13 (below), suggests that majority (53.3\%) of the respondents believe that media partially effect their opinions. Maximum of these respondents are good in studies $(66.6 \%)$, belong to arts faculty $(60 \%)$ Followed by (25\%) who believe media completely influence their opinions while $(20 \%)$ believe that media doesn't affect their opinions at all. These respondents come from urban areas, belong to science faculty and are excellent in studies. 


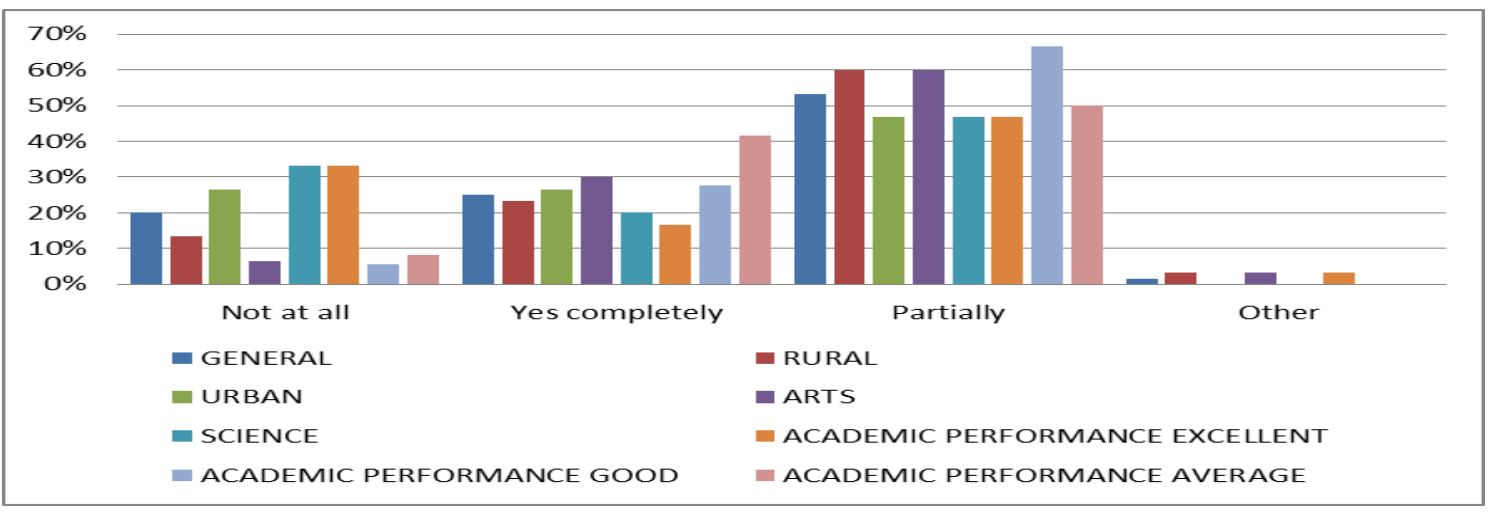

Figure 13 Data of Media consumption habits of college going women youth

\section{Media through which women hear about new products or services}

Figure 14(below), shows that out of the total sample of 60, maximum of the respondents (61.6\%) hear about new products/services through TV , followed by $(28.3 \%)$ which get informed via newspapers, then (16.6\%) who chose Internet and minimum (3.3\%) of the total respondents indicated radio to be the medium through which they hear about new products/services

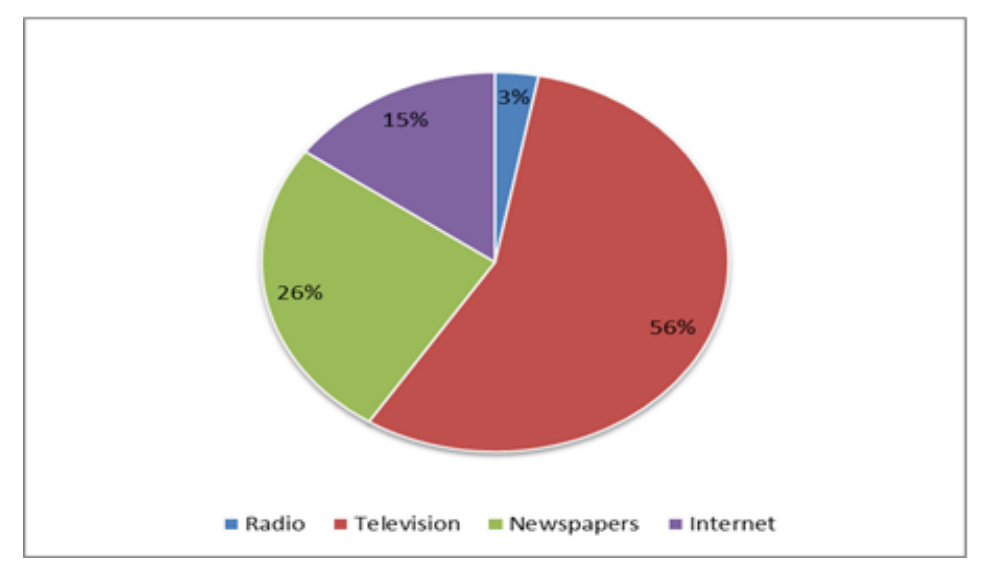

Figure 14 Data of Media consumption habits of college going women youth

\section{Conclusion}

The study examined media consumption habits of young women in Kashmir. As the media patterns are changing, media consumption and usage patterns are evolving for the audience especially younger ones. The key findings of this study are manifold and based on those findings the following conclusions are made.

\section{Media consumption and usage}

\section{Newspapers}

Newspapers are the most preferred medium for news among women followed by TV, Internet and Radio. Internet, and radio credibility is still low and not used so commonly as sources of information and current affairs.

Maximum respondents get access to newspapers through buying every time followed by magazines, and CD.DVD'S. The interesting fact is maximum of these respondents who buy magazines/CD belong to rural 
areas, while those who subscribe or access newspapers online come from urban areas, and are excellent in studies.

An extensive proportion of youth from urban areas read newspapers. While those coming from rural areas don't show interest in reading newspapers on a daily basis but prefer to read them few times a week or even a month. These students are average in studies as compared to their excellent counterparts who read newspapers daily. These patterns suggest that media outlets need to consider this accessibility and devise strategies to increase their younger audience.

\section{Television}

TV is the medium which majority prefer to remove boredom from followed by the internet. Programmes such as reality shows and soap operas based on romantic themes are the first preference of young women, followed by movies and news.

Categories such as business, agriculture, and horror receive the least attention from women youth.

Majority of women youth watch Television every day at least for 1-2 hrs. Women should be offered something great in return so that they start spending more time on the content provided. It should be a qualitative experience.

TV is the most popular medium to receive information regarding new products/ services, followed by internet and radio. Advertisements regarding beauty products top the range such as Ponds, Lakme, VLCC etc. Potential marketers can increase their brand's social currency by knowing what their target group needs, and how they see it? Ultimately increasing sales.

It is evident TV is consumed more for entertainment purposes. Future research might study the uses and gratifications on a wider scale. Marketers can further gauge how these choices are purposeful in gaining the attention of their target youth.

\section{Radio}

Radio listenership is more prominent among women who belong to rural areas than their urban counterparts, who do not listen to the radio in the traditional format but on mobile phones via internet radio.

Majority of them tune in to radio for music. Programmes such as education, health, dramas are given less attention. Efforts are thus required to entice the urban audience to tune into the radio.

\section{Internet}

The internet is accessed daily with majority spend at least $1-2 \mathrm{hrs}$ on a single session at their homes via the personal connection. This portion belongs to urban areas while those who access the internet at internet cafes and community centres belong to rural areas.

Mobile phones are widely used to access the internet via home connection followed by laptops/desktops. The use of mobile phones is evolving and making its way into the digital arena giving brands an opportunity to create content optimized for mobile, corresponding to the needs of young women.

Women from urban section show an inclination towards WIFI and broadband connection, while none from rural areas tend to possess it. Further research can thus be conducted to know the drawbacks in connectivity and ascertain the access and reach patterns to work further towards building a rich and interactive audience. 
A sizeable portion of young women classified internet as the most preferred platform for academic purposes. This tends to be an opportunity for educationist to use smart teaching techniques to reach their audience and widen the scope for more development in the field of education.

Social Networking is the second most popular activity on the Internet. Among which majority tend to stay online even while watching TV or listening to music. Women's impulse to multitask offers marketers another great potential to sell their brands to the right audience at the right time.

Facebook wins over all other social networking sites on the internet.

\section{News sources}

Newspapers are the first preference of young women who want to stay updated on local issues/happenings.TV is the preferred medium to receive information regarding national affairs and internet is accessed to stay updated with international happenings/issues.

\section{Effects of Media}

Attitudes: Analysis shows that youth is psychologically very attached to media. The majority believe how they won't feel good if they are barred from using any source of the media. They expressed their feelings in terms such as socially cut off, sad, annoyed, bad bored, detached isolated, lonely, death, and lost. However, some say they will feel good - comfortable, interested in studies.

Academics: There is a positive association between media and academic lives. Majority believe the internet has led to improvement in their academic lives keeping them updated and aware. However, they also believe they have become more addictive to it and are somehow dependent on it.

Family relationships: A fairly good percentage believes that internet leads to detachment as well as connection with friends and family. This digital technology has created a shift in media consumption habits of women and how they relate to their families and social contacts. This is an opportunity for marketers to measure how the audience can be persuaded further with messages of humanity and family connections.

Media as an opinion leader: Media is considered to partially influence women's opinions followed by those who believe it completely does. Knowing this fact, marketers can embrace, encourage and augment this media consumption pattern.

Personality disorders: Women believe that people tend to behave differently on Social networking sites. Terms to explain this behaviour: reserved, show off, fake identity, formal, pretence, try to behave more sophisticated than in their real lives and at the same time also become more expressive as the internet provides anonymity.

Given these findings, a marketer should not only acknowledge but also understand and interpret these perceptions simultaneously to know what's going in women's heads so as to have a better communication with their target audience.

\section{Note/ limitation}

This study focuses only on college-going women from a single college, which limits its generalizability. However, expanding the range of participants in near future will improve the reliability of findings and give a broader picture into the media consumption patterns of media among women audience. 


\section{References}

Burst study, P 2007, Survey: To Reach College Students, Brands Need to Use Internet, viewed 21 April 2014, https://www.marketingcharts.com/television-1389.

Chan.Sylvia, Hjeoon Rim, Zebra Amy., (2013), Mobile News Adoption among Young Adults- Examining the roles of Perceptions, News Consumption, and media usage, viewed 27 April 2014, http://journals.sagepub.com/doi/10.1177/1077699012468742

Ford, Clark (2010), News Consumption Habits of Students at the University of Nebraska, viewed 27 September 2014, https://digitalcommons.unl.edu/cgi/viewcontent.cgi?article=1010\&context=journalismdiss

IPSAS (2011): Kenyan Media consumption Habits, Viewed 22 April 2014, https://medium.com/@kasiinsight/media-consumption-in-kenya-2d0f9e97ca98

Larose. Robert (2003): Unregulated Internet Usage- Addiction, Habit or Deficient Self-regulation?, viewed 22 april 2014, https://scholars.opb.msu.edu/en/publications/unregulated-internet-usage-addiction-habit-or-deficientself-regu-4

Levine.Laura, Waite. Braidley and Bauman.Laura (2007): Electronic Media Use, Reading and academic distractibility in college youth, viewed 20 April 2014, http://users.clas.ufl.edu/msscha/PremedCSS/electronic_media_distractibility_college.pdf

Lyang.Yu, Chen.Weii, Wang.Qingya: The Effect Of Social Media On college Students, ed 2011, viewed 24 April 2014, http://scholarsarchive.jwu.edu/cgi/viewcontent.cgi?article=1004\&context=mba_student

Napoli. Julie, Ewing. Michael (2008): The Net Generation, viewed 2 May 2016, https://www.tandfonline.com/doi/ref/10.1300/J046v13n01_03?scroll=top

Ofcom-Adult media use and attitudes report, ed. 2012, viewed 22 april 2014, https://www.ofcom.org.uk/_data/assets/pdf_file/0028/74773/adults-media-use-2012.pdf

Perse. Elizabeth ed. 2009: Students and Cultivation, viewed 28 April 2014, https://www.researchgate.net/profile/Elizabeth_Perse/publication/233944784_Soap_Opera_Viewing_Patterns_o f_College_Students_and_Cultivation/links/09e4150d322072dddf000000/Soap-Opera-Viewing-Patterns-ofCollege-Students-and-Cultivation.pdf

Vahlberg.Vivai (2010): Fitting into their lives, viewed 2 May 2014, https://www.americanpressinstitute.org/wpcontent/uploads/2013/09/NIE_Fitting_into_their_lives.pdf

Xavier. Garcia, Espelt. Albert and Nebot.Manel (2013): Factors associated with media use among adolescents- a multilevel approach, viewed 28 April 2014, https://watermark.silverchair.com/ckt013.pdf 